\title{
Materia organiczna rozproszona w ciemnych turbidytach górnego eocenu płaszczowiny śląskiej (Karpaty zewnętrzne, Polska)
}

\author{
Marta Waliczek ${ }^{1}$, Anna Waśkowska ${ }^{1}$, Grzegorz Machowski ${ }^{1}$
}
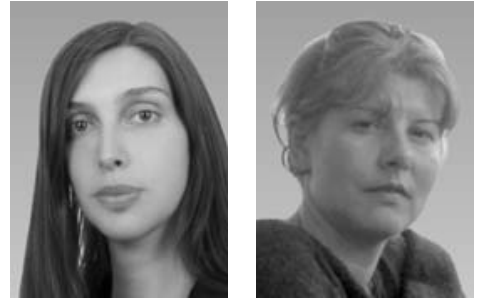

M. Waliczek
A. Waśkowska

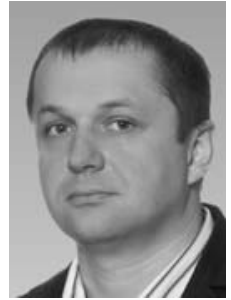

G. Machowski

Organic matter dispersed in the Upper Eocene dark turbidities of the Silesian Nappe (Outer Carpathians, Poland). Prz. Geol., 69: 458-462; doi: $10.7306 / 2021.31$

A b s t r a c t. In this study, we apply microscopic analysis to evaluate the maturity of organic matter and characterise the macerals dispersed in the Upper Eocene shale samples from the Hieroglyphic Formation (Silesian Nappe, Outer Carpathians). The mean vitrinite reflectance values indicate the presence of organic matter immature to hydrocarbon generation $\left(R_{o} \approx 0.43 \%\right)$. The main organic component dispersed in analysed samples is vitrinite, characteristic of kerogen type III.

Keywords: organic matter, vitrinite reflectance, dark shales, Silesian Nappe, Outer Carpathians

Mikroskopowa analiza materii organicznej jest powszechnie stosowana do określania dojrzałości termicznej i składu macerałowego materii organicznej (MO) rozproszonej w skałach osadowych (Taylor i in., 1998). Podstawowym wskaźnikiem petrologicznym, wykorzystywanym w tej metodzie, jest refleksyjność huminitu i witrynitu $\left(\mathrm{R}_{\mathrm{o}} \%\right)$ (Hackley, Cardott, 2016 i literatura cytowana). Na podstawie szacunkowej analizy komponentów organicznych (macerałów) występujących w próbce można również wyznaczyć typ kerogenu dominujący w skale (Taylor i in., 1998).

W artykule opisano wyniki badań mikroskopowych materii organicznej zawartej w 16 próbkach skał należących do formacji hieroglifowej w płaszczowinie śląskiej. W formacji tej występuje kompleks ciemnych turbidytów zdeponowanych przed główną fazą sedymentacji ciemnych utworów mułowcowych formacji menilitowej, które są ważnymi skałami macierzystymi dla węglowodorów karpackich (np. Kotarba, Koltun, 2006). Celem analizy było określenie stopnia dojrzałości materii organicznej, identyfikacja składników organicznych oraz wyznaczenie maksymalnych paleotemperatur oddziałujących na skały formacji hieroglifowej. Wyniki badań materii organicznej mogą uzupełnić dane uzyskane we wcześniejszych jej analizach (Zielińska i in., 2017, 2020; Ziemianin, 2017; Ziemianin i in., 2015; Waliczek i in., 2019, 2021 i literatura cytowana) i posłużyć do dalszych prac nad rozpoznaniem termicznej historii Karpat zewnętrznych.

\section{OBSZAR BADAŃ I MATERIAL}

Obszar badań jest zlokalizowany w południowym obrzeżeniu płaszczowiny śląskiej (ryc. 1A-B) na SE od Krakowa (Pl - 1992; N: 4948’12.16”, E: 20¹0’27.82). Ciaggły profil utworów paleogeńskich płaszczowiny śląskiej odsłania się w dolinie Stradomki, gdzie opróbowa- no kompleks skał z górnej części formacji hieroglifowej (ryc. 1C-D), o miąższości 20 m (Waśkowska, 2015; Waśkowska i in., 2016). Kompleks ten składa się z utworów turbidytowych, w których dominują brązowe, brunatne i ciemnoszare mułowce, przeławicające cienkie mułowce zielone, drobnoziarniste i bardzo drobnoziarniste piaskowce oraz bentonity (ryc. 1E). Utwory te zostały zdeponowane w głębokowodnym basenie śląskim we wczesnym bartonie i charakteryzują się podwyższoną zawartością materii organicznej - całkowita zawartość węgla organicznego TOC (total organic carbon) osiaga w nich do $2,85 \%$. Sedymentacja utworów eoceńskich odbywała się w warunkach niskoenergetycznych, przy niedoborze tlenu oraz ograniczonym dopływie materiału klastycznego (Waśkowska, 2015).

\section{METODYKA}

Mikroskopowe badania materii organicznej rozproszonej w eoceńskich łupkach płaszczowiny śląskiej przeprowadzono przy użyciu mikroskopu AxioImager Alm firmy Carl Zeiss, sprzężonego z zestawem fotometrycznym MSP 200 firmy $J \& M \mathrm{GmbH}$, umożliwiającym pomiar refleksyjności witrynitu. Wyniki badań przedstawiono w formie uśrednionej wartości pomiarów refleksyjności witrynitu $\left(\mathrm{R}_{\mathrm{o}}\right)$. Refleksyjność witrynitu zmierzono zgodnie z wytycznymi normy ASTM D 7708-11 (2011).

Analizę macerałów przeprowadzono w świetle odbitym białym (identyfikacja macerałów z grupy witrynitu i inertynitu) oraz UV (identyfikacja macerałów z grupy liptynitu). Klasyfikację macerałów przyjęto zgodnie z ustaleniami ICCP - International Committee for Coal and Organic Petrology (International..., 1998; 2001; Pickel i in., 2017). Analizę ilościową materii organicznej wykonano zgodnie z zaleceniami Taylor i in. (1998), przeliczając ok. 300 punktów intersekcyjnych na powierzchni każdego zgładu.

\footnotetext{
${ }^{1}$ AGH Akademia Górniczo-Hutnicza w Krakowie, Wydział Geologii, Geofizyki i Ochrony Środowiska, al. Mickiewicza 30, 30-059 Kraków; waliczek@agh.edu.pl
} 


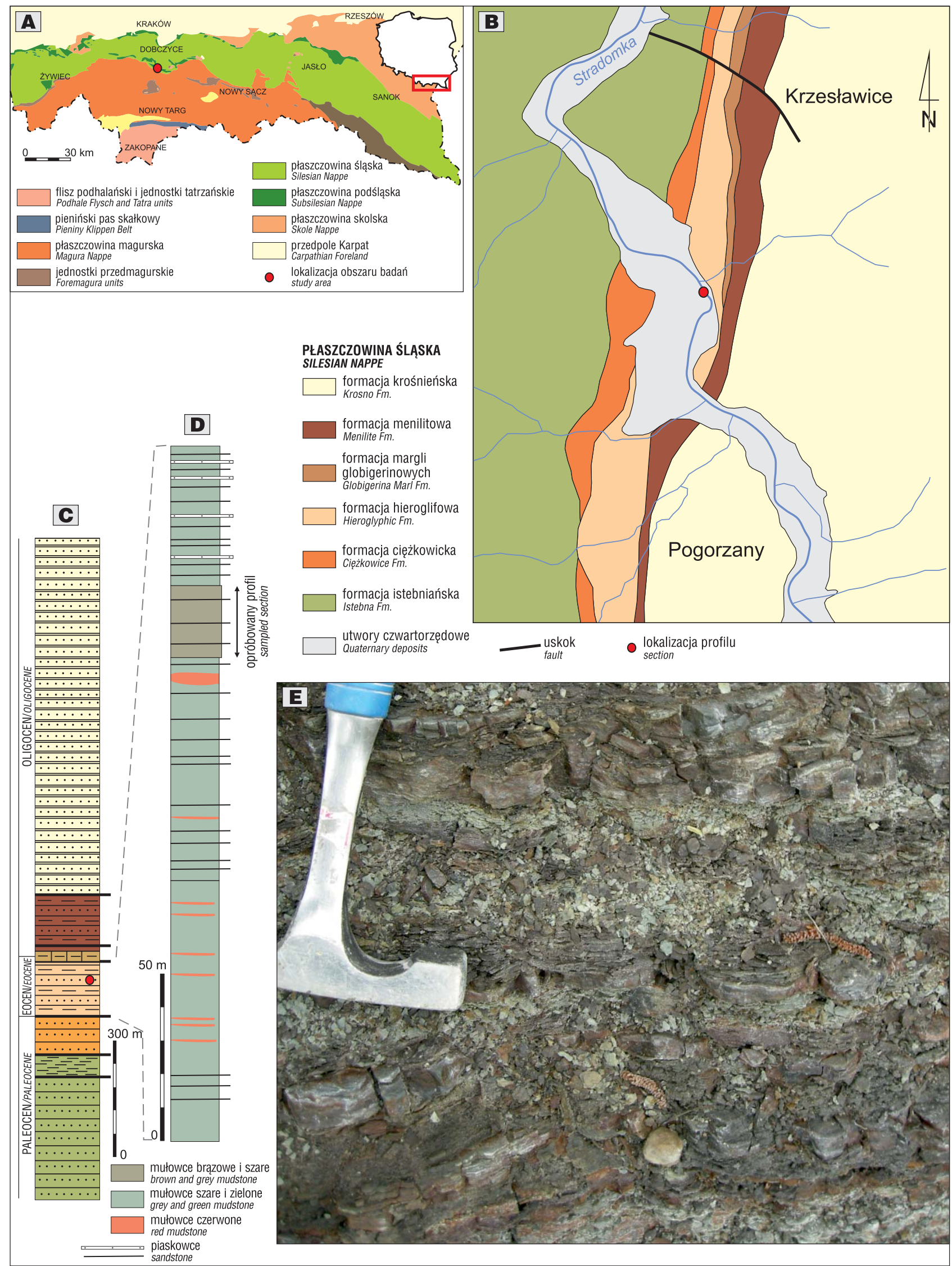

Ryc. 1. A, B - Lokalizacja poboru próbek skał do badań na tle Karpat zewnętrznych oraz na szczegółowym szkicu geologicznym okolicy Krzesławic. C, D - Pozycja badanego kompleksu skał turbidytowych w profilu litostratygraficznym płaszczowiny śląskiej oraz formacji hieroglifowej. E - Ciemne turbidyty odsłaniające się w korycie Stradomki, fm. hieroglifowa, górny eocen, płaszczowina śląska

Fig. 1. A, B - Location of rock sampling in the Outer Carpathians and in a detailed geological sketch-map of the Krzesławice area. C, DPosition of the complex on the lithostratigraphic log of the Silesian Nappe and the Hieroglyphic Formation. E - Dark turbidites exposed in the Stradomka riverbed, Hieroglyphic Fm., Upper Eocene, Silesian Nappe 
Tab. 1. Refleksyjność witrynitu, skład petrograficzny rozproszonej materii organicznej i maksymalne paleotemperatury eoceńskich łupków z doliny Stradomki

Table 1. Vitrinite reflectance, petrographic composition of dispersed organic matter and maximum palaeotemperatures of Upper Eocene shales from the Stradomka valley

\begin{tabular}{|c|c|c|c|c|c|c|c|c|}
\hline \multirow[t]{2}{*}{$\begin{array}{l}\text { Próbka } \\
\text { Sample }\end{array}$} & \multirow{2}{*}{$\begin{array}{l}\text { Średnia wartość } \\
\text { refleksyjności } \\
\text { witrynitu } \\
\text { Average vitrinite } \\
\text { reflectance value } \\
\mathrm{R}_{0}[\%]\end{array}$} & \multirow[t]{2}{*}{$\begin{array}{c}\text { Liczba } \\
\text { pomiarów } \\
\text { Number of } \\
\text { measurements }\end{array}$} & \multirow[t]{2}{*}{$\begin{array}{l}\text { Odchylenie } \\
\text { standardowe } \\
\text { Standard } \\
\text { deviation }\end{array}$} & \multirow{2}{*}{$\begin{array}{c}\text { Zakres } \\
\text { refleksyjności } \\
\text { witrynitu } \\
\text { Vitrinite reflectance } \\
\text { range } \\
\mathbf{R}_{\mathbf{0}}[\%]\end{array}$} & \multicolumn{3}{|c|}{$\begin{array}{c}\text { Sklad petrograficzny } \\
\text { rozproszonej materii organicznej } \\
\text { Petrographic composition } \\
\text { of dispersed organic matter } \\
{[\%]}\end{array}$} & \multirow[t]{2}{*}{$\begin{array}{l}\mathbf{T}_{\max } \\
{\left[{ }^{\circ} \mathbf{C}\right]}\end{array}$} \\
\hline & & & & & $\begin{array}{l}\text { Witrynit } \\
\text { Vitrinite }\end{array}$ & $\begin{array}{l}\text { Inertynit } \\
\text { Inertinite }\end{array}$ & $\begin{array}{l}\text { Liptynit } \\
\text { Liptinite }\end{array}$ & \\
\hline Stradomka 2 & 0,40 & 37 & 0,03 & $0,32-0,45$ & 55 & 8 & 36 & 62 \\
\hline Stradomka 4 & 0,40 & 52 & 0,04 & $0,33-0,52$ & 81 & 3 & 26 & 62 \\
\hline Stradomka 6 & 0,41 & 53 & 0,07 & $0,29-0,58$ & 70 & 6 & 24 & 64 \\
\hline Stradomka 7 & 0,41 & 53 & 0,05 & $0,32-0,49$ & 67 & 2 & 31 & 64 \\
\hline Stradomka 9 & 0,44 & 90 & 0,06 & $0,29-0,59$ & 70 & 3 & 27 & 69 \\
\hline Stradomka 11 & 0,48 & 80 & 0,07 & $0,37-0,70$ & 71 & 2 & 27 & 76 \\
\hline Stradomka 14 & 0,41 & 70 & 0,05 & $0,32-0,58$ & 61 & 4 & 35 & 64 \\
\hline Stradomka 16 & 0,43 & 50 & 0,04 & $0,34-0,53$ & 68 & 5 & 27 & 67 \\
\hline Stradomka 20 & 0,45 & 70 & 0,04 & $0,32-0,52$ & 71 & 10 & 19 & 71 \\
\hline Stradomka 22 & 0,46 & 70 & 0,08 & $0,30-0,60$ & 78 & 7 & 15 & 73 \\
\hline Stradomka 24 & 0,43 & 63 & 0,05 & $0,33-0,61$ & 81 & 6 & 13 & 67 \\
\hline Stradomka 26 & 0,44 & 80 & 0,06 & $0,34-0,59$ & 70 & 5 & 25 & 69 \\
\hline Stradomka 28 & 0,45 & 50 & 0,07 & $0,32-0,60$ & 66 & 11 & 23 & 71 \\
\hline Stradomka 30 & 0,44 & 70 & 0,06 & $0,35-0,62$ & 67 & 10 & 23 & 69 \\
\hline Stradomka 32 & 0,43 & 12 & 0,04 & $0,39-0,49$ & 48 & 36 & 16 & 67 \\
\hline Stradomka 34 & 0,47 & 36 & 0,09 & $0,31-0,58$ & 56 & 30 & 14 & 75 \\
\hline
\end{tabular}

$\mathbf{T}_{\max }$ - maksymalna paleotemperatura oszacowana na podstawie wskaźnika $\mathrm{R}_{\mathrm{o}}$ z zastosowaniem logarytmu $\mathrm{T}_{\max }=\left(\ln \left(\mathrm{R}_{\mathrm{o}}\right)+1,68\right) / 0,0124($ Barker, Pawlewicz, 1994) / maximum palaeotemperature estimated based on the $R_{o}$ factor using equation $T_{\max }=\left(\ln \left(R_{o}\right)+1.68\right) / 0.0124$ (Barker, Pawlewicz, 1994)

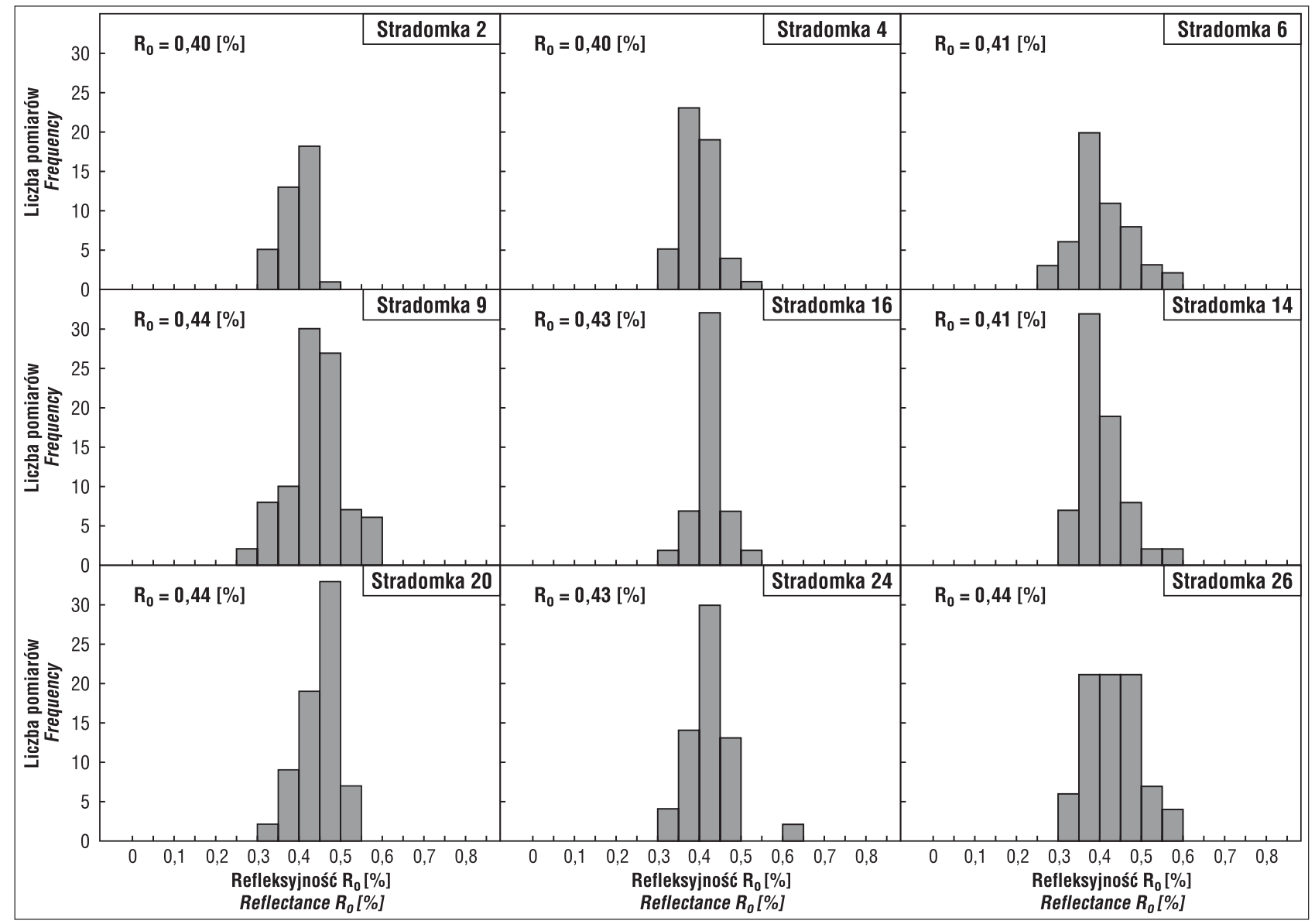

Ryc. 2. Refleksyjność witrynitu $\mathrm{R}_{\mathrm{o}}[\%]$ w wybranych próbkach eoceńskich łupków z doliny Stradomki

Fig. 2. Vitrinite reflectance $R_{o}[\%]$ in selected samples of Eocene shales from the Stradomka valley 


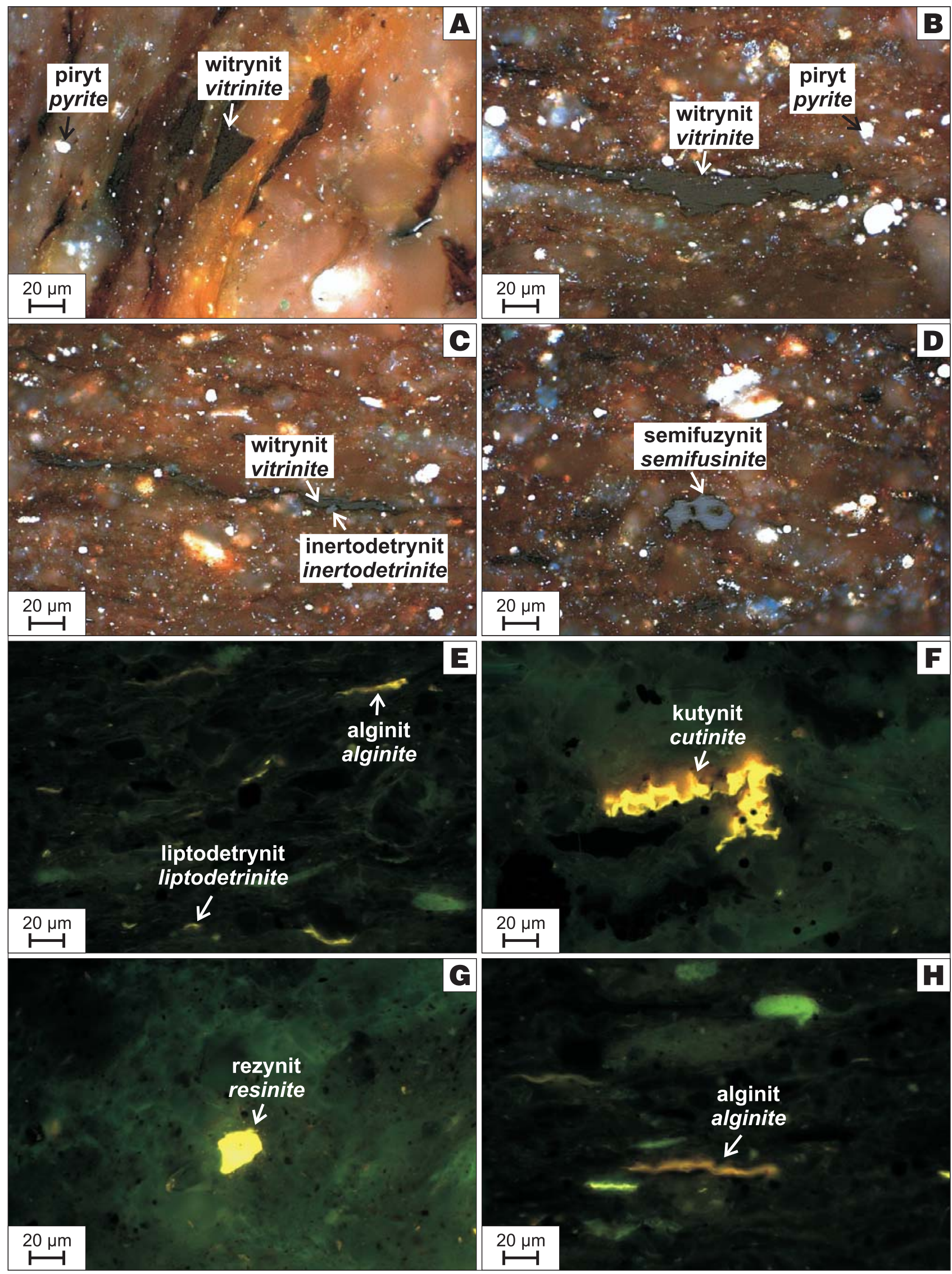

Ryc. 3. Mikrofotografie materii organicznej rozproszonej w ciemnych turbidytach górnego eocenu: zdjęcia A (próbka Stradomka 2), B, C i D (próbka Stradomka 9) wykonano w świetle odbitym białym; zdjęcia E, H (próbka Stradomka 9), F (próbka Stradomka 26) oraz G (próbka Stradomka 28) wykonano w świetle UV, w imersji olejowej

Fig. 3. Microphotographs of organic matter dispersed in the Late Eocene dark turbidites: photos A (sample Stradomka 2), B, C and D (sample Stradomka 9) - reflected white light; photos E, H (sample Stradomka 9), F (sample Stradomka 26) and G (sample Stradomka 28) UV light, oil immersion 
Mikrofotografie materii organicznej wykonano za pomocą kamery cyfrowej AxioCamMRc 5, obsługiwanej przez oprogramowanie AxioVision firmy Carl Zeiss z zastosowaniem obiektywu imersyjnego o 50-krotnym powiększeniu.

Maksymalne paleotemperatury oddziałujące na badane skały oszacowano, stosując logarytm Barkera i Pawlewicza (1994).

\section{WYNIKI}

Refleksyjność witrynitu w górnoeoceńskich utworach formacji hieroglifowej, mierzona punktowo, osiaga od 0,29 do $0,62 \% R_{0}$. Średnia refleksyjność witrynitu analizowanych próbek wynosi $0,43 \% \mathrm{R}_{\mathrm{o}}$ i mieści się w przedziale od 0,40 do $0,48 \% \mathrm{R}_{\mathrm{o}}$ (tab. 1, ryc. 2). Refleksyjność witrynitu $<0,5 \% \mathrm{R}_{\mathrm{o}}$ jest charakterystyczna dla utworów o niskim stopniu dojrzałości termicznej (Peters, Cassa, 1994) i wskazuje, że maksymalne paleotemperatury, jakie oddziaływały na badane skały osadowe, mieściły się $\mathrm{w}$ granicach $62-76^{\circ} \mathrm{C}$ (tab. 1), a średnio wynosiły $68^{\circ} \mathrm{C}$ (Barker, Pawlewicz, 1994).

Pomierzone średnie wartości $\mathrm{R}_{0}$ charakteryzują się w większości niskim odchyleniem standardowym (tab. 1). Rozkład pomiarów refleksyjności witrynitu rozproszonego $\mathrm{w}$ analizowanych skałach, przedstawiony $\mathrm{w}$ formie reflektogramów, jest w większości jednomodalny (ryc. 2). Zarówno kształt histogramów, jak i mały rozrzut wartości $\mathrm{R}_{\mathrm{o}}$ mogą wskazywać na poprawne pomiary refleksyjności witrynitu.

Macerały z grupy witrynitu (ryc. 3. A, B, C) stanowią w analizowanych próbkach od 48 do $81 \% \mathrm{MO}$ (średnio $68 \%$ ) i są reprezentowane głównie przez kolotelinit, pojawiający się w formie lamin, żyłek oraz okruchów. Grupa liptynitu (od 14 do 36\% MO, średnio 24\%) występuje jako alginit (ryc. 3E-H), liptodetrynit (ryc. 3E), kutynit (ryc. 3F) i sporadycznie rezynit (ryc. 3G). Macerały z grupy inertynitu stanowią od 3 do $36 \%$ MO (średnio 9\% MO) i występują w postaci inertodetrynitu, fuzynitu oraz semifuzynitu (ryc. 3D).

\section{PODSUMOWANIE}

Pomierzone wartości wskaźnika refleksyjności witrynitu górnoeoceńskich, ciemnych utworów formacji hieroglifowej są charakterystyczne dla materii organicznej o niskiej dojrzałości termicznej, niezdolnej do generowania węglowodorów. Maksymalne temperatury oddziałujące na analizowane skały nie przekraczały $62-76^{\circ} \mathrm{C} . \mathrm{W}$ składzie materii organicznej analizowanych próbek dominuje materiał humusowy, którego głównym składnikiem jest witrynit, wskazujący na III typ kerogenu. W mniejszych ilościach występują macerały z grupy liptynitu. Fragmenty inertynitu pojawiają się najrzadziej.

Autorzy składają serdecznie podziękowania Recenzentom: Profesorowi Leszkowi Marynowskiemu oraz Profesorowi Grzegorzowi Nowakowi za cenne uwagi i wskazówki dotyczące pracy. Prezentowane w artykule wyniki badań uzyskano w ramach realizacji projektu badawczego o akronimie ShaleCarp w progra- mie Blue Gas II, finansowanego przez Narodowe Centrum Badań i Rozwoju (BG2/ShaleCarp/14) oraz w ramach prac badawczych Wydziału Geologii, Geofizyki i Ochrony Środowiska AGH nr 16.16.140.315.

\section{LITERATURA}

ASTM D7708-11, 2011 - Standard Test Method for Microscopical Determination of the Re-flectance of Vitrinite Dispersed in Sedimentary Rocks. American Society For Testing And Materials International, West Conshohocken, doi: 10.1520/D7708-11

BARKER C.E., PAWLEWICZ M.J. 1994 - Calculation of vitrinite reflectance from thermal histories and peak temperatures:a comparison of methods. [W:] Mukhopadhyay, P.K., Dow W.G. (red.), Vitrinite Reflectance as Maturity Parameter: Applications and Limitations. American Chemical Soc. Symp. Ser.: 570: 216-229.

HACKLEY P.C., CARDOTT B.J. 2016 - Application of organic petrography in North American shale petroleum systems: a review. Intern. J. Coal Geol., 163: 8-51.

INTERNATIONAL Committee for Coal and Organic Petrology (ICCP). 1998 - The new vitrinite classification (ICCP System 1994). Fuel, 77: 349-358.

INTERNATIONAL Committee for Coal and Organic Petrology (ICCP). 2001 - The new inertinite classification (ICCP System 1994). Fuel, 80: 459-471.

KOTARBA M.J., KOLTUN Y.V. 2006 - The origin and habitat of hydrocarbons of the Polish and Ukrainian parts of the Carpathian province. [W:] Golonka J., Picha F.J. (red.) - The Carpathians and their foreland: Geology and hydrocarbon resources. AAPG Memoir, 84: 395-442.

PETERS K.E., CASSA M.R. 1994 - Applied Source-Rock Geochemistry. [W:] Magoon L.B., Dow W.G. (red.), The Petroleum System. From Source to Trap, American Association of Petroleum Geologists, Tulsa: 93-120.

PICKEL W., KUS J., FLORES D., KALAITZIDIS S., CHRISTANIS K., CARDOTT B.J., MISZ M., KENNAN R.S., HENTSCHEL A., HAMOR-VIDO M., CROSSDALE P., WAGNER N. 2017 - Classification of liptinite - ICCP System 1994. Intern. J. Coal Geol., 69: 40-61.

TAYLOR G.H., TEICHMÜLLER M., DAVIS A., DIESSEL C.F.K., LITTKE R., ROBERT P. 1998 - Organic Petrology. Gerbrüder Bornträger, Berlin, Germany: 704

WALICZEK M., MACHOWSKI G., WIECEAW D., KONON A., WANDYCZ P. 2019 - Properties of solid bitumen and other organic matter from Oligocene shales of the Fore-Magura Unit in Polish Outer Carpathians: Microscopic and geochemical approach. Intern. J. Coal Geol., 210: 103206, https://doi.org/10.1016/j.coal. 2019.05.013.

WALICZEK M., MACHOWSKI G., POPRAWA P., ŚWIERCZEWSKA A. WIECEAW D. 2021 - A novel VRo, T and S indices conversion formulae on data from the fold-and-thrust belt of the Western Outer Carpathians (Poland). Intern. J. Coal Geol., 234: 103672 https://doi.org/10.1016/j.coal.2020.103672.

WAŚKOWSKA A. 2015 - Stratigraphy of the Hieroglyphic beds with „black Eocene” facies from the Silesian Nappe (Outer Flysch Carpathians, Poland) Ann. Soc. Geol. Pol., 85: 321-343.

WAŚKOWSKA A., GOLONKA J., MACHOWSKI G., STEFANIUK M., WALICZEK M. 2016 - Organic-rich deposits in the Carpathian Middle Eocene (Silesian Nappe). AAPG European regional conference \& exhibition: petroleum systems of Alpine-Mediterranean fold belts and basins: $19^{\text {th }}-20^{\text {th }}$ May, Bucharest, Romania.

ZIELIŃSKA M. 2017 - Organic-matter vitrinite reflectance variability in the Outer Carpathians, Poland: relationship to tectonic evolution. Geol. Quart., 61: 214-226.

ZIELIŃSKA M., FABIAŃSKA M., WIECŁAW D., MISZ-KENNAN M. 2020 - Comparative petrography and organic geochemistry of different types of organic matter occurring in the Outer Carpathians rocks. Geol. Quart., 64, 165-184.

ZIEMIANIN K. 2017 - Petrographic-geochemical characterization of the dispersed organic matter in Menilite shales from the Silesian Unit in the Carpathian Mountains of SE Poland. Nafta-Gaz, 11: 835-842. ZIEMIANIN K., BRZUSZEK P., SŁOCZYŃSKI T., JANKOWSKI L. 2015 - Dispersed organic matter in shales from Menilite Beds within Polish Outer Carpathians - preliminary diagnosis. Nafta-Gaz, 9: 615-623.

Praca wpłynęła do redakcji 27.03.2021 r.

Akceptowano do druku 12.05.2021 r. 